Stoltz, S.B. Why no guidelines for behavior modification? Journal of Applied Bebavior Analysis, 1977, 10, 541-547.

Whaley, D.L., and Malott, R.W. Elementary Principles of Behavior. New York: Appleton-Century-Crofts, 1971.

Wolf, M.M. Social validity: The case for subjective measurement of how applied behavior analysis is finding its heart. Journal of Applied Bebavior Analysis. 1978, 11, 203-214.

\title{
B.F.S.A. Organizational Decisions
}

The 1978 B.F.S.A. organizational meeting was held in Chicago at the May MABA meetings. It was decided to publish both a semi-annual journal and a quarterly newsletter, and elect an editor of each and a national secretary. While these offices would be up for election at each midyear ABA meetings, tenure in each office would be by calendar year.

Harry Kent of Western Michigan University was elected editor of the newsletter for the remainder of 1978 and for 1979. Joe Morrow of California State University, Sacramento was elected editor of the journal for the remainder of 1978 and for 1979. Gary Gant of Western Michigan was elected National Secretary for 1978 and Saranne Oberman, University of Kansas was elected National Secretary for 1979.

Election for these offices for 1980 will be conducted at the 1979 BFSA organizational meeting to be held at the June 15-19, 1979 A.B.A. meetings in Dearborn, Michigan. 